\title{
Configuration and Assessment of a Senior Level Course in Biometric Systems
}

\section{Dr. Ravi P. Ramachandran, Rowan University}

Dr. Ravi P. Ramachandran received a B.Eng degree with great distinction from Concordia University in 1984, a M.Eng degree from McGill University in 1986, and a Ph.D. from McGill University in 1990. From October 1990 to December 1992, he worked at the Speech Research Department at AT\&T Bell Laboratories. From January 1993 to August 1997, he was a research assistant professor at Rutgers University. He was also a senior speech scientist at T-Netix from July 1996 to August 1997. He has been a professor in the Department of Electrical and Computer Engineering at Rowan University since September 2006. He has served as a consultant to T-Netix, Avenir Inc. and Motorola. From September 2002 to September 2005, he was an associate editor for the IEEE Transactions on Speech and Audio Processing and was on the Speech Technical Committee of the Signal Processing society. Since September 2000, he has been on the Editorial Board of the IEEE Circuits and Systems Magazine. Since May 2002, he has been on the Digital Signal Processing Technical Committee for the Circuits and Systems society. His research interests are in digital signal processing, speech processing, pattern recognition, biometrics and filter design.

\section{Dr. Robi Polikar, Rowan University \\ Dr. Kevin D. Dahm, Rowan University}

Dr. Kevin Dahm is an associate professor of Chemical Engineering at Rowan University. He received his B.S. from WPI in 1992 and his Ph.D. from MIT in 1998. His primary areas of pedagogical scholarship are teaching design, process simulation in the curriculum, assessment of student learning and teaching engineering economics. He has received the 2011 Mid-Atlantic Section Outstanding Teaching Award, the 2005 Corcoran Award, the 2004 Fahien Award and the 2003 Martin Award from ASEE.

\section{Prof. Robert M Nickel, Bucknell University}

Robert. M. Nickel received the Diplom-Ing. degree in Electrical Engineering from the RheinischWestflische Technische Hochschule (RWTH) in Aachen, Germany in 1994 and the M.S. degree in electrical engineering and the Ph.D. degree from the University of Michigan, Ann Arbor, in 1997 and 2001, respectively. During the 2001-2002 academic year, he was an adjunct faculty in the Department of Electrical Engineering and Computer Science at the University of Michigan. From 2002 until 2007, he was a faculty member at the Pennsylvania State University at University Park. Since the fall of 2007, he has been a faculty member at Bucknell University's Electrical Engineering Department. His main research interests include speech signal processing and general signal theory.

\section{Dr. Richard J. Kozick, Bucknell University \\ Dr. Sachin Shetty, Tennessee State University}

Dr. Sachin Shetty is currently an assistant professor in the Department of Electrical and Computer Engineering at Tennessee State University. He received his Ph.D. degree in Modeling and Simulation from Old Dominion University in 2007. His research interests lie at the intersection of computer networking, network security and machine learning. Recently, he has been working on security issues in cloud computing, cognitive radio networks, and wireless sensor networks. Over the years, he has secured funding from NSF, AFOSR, DOE, DHS, TBR and local industry for research and educational innovations. He has authored and co-authored over 30 technical refereed and non-refereed papers in various conferences, international journal articles, book chapters in research and pedagogical techniques. He is the director of the Cyber Defense and Security Visualization Laboratory.

\section{Dr. Ying Tang, Rowan University}

Dr. Ying Tang received B.S. and M.S. degrees from Northeastern University in P. R. China in 1996 and 1998, respectively. She also earned a Ph.D. degree from the New Jersey Institute of Technology in 
2001. She is currently an associate professor of Electrical and Computer Engineering at Rowan University. Her research interests include virtual reality, artificial intelligence, and modeling and scheduling of computer-integrated systems. Dr. Tang has led or participated in several research and education projects funded by National Science Foundation, U.S. Department of Transportation, U.S. Navy, the Charles A. and Anne Morrow Lindbergh Foundation, the Christian R. and Mary F. Lindback Foundation, and industry firms. Her work has resulted in more than 80 journal and conference papers and book chapters. Dr. Tang is very active in adapting and developing pedagogical methods and materials to enhance engineering education. Her most recent educational research includes the collaboration with Tennessee State University and local high schools to infuse cyber-infrastructure learning experience into the pre-engineering and technology-based classrooms, and the collaboration with community colleges to develop interactive games in empowering students with engineering literacy and problem-solving.

\section{Dr. Steven H Chin, Rowan University}

Dr. Steven H. Chin currently serves as interim dean of Engineering at Rowan University. He has a Bachelor of Science degree from Rutgers University, a Master of Science degree from Johns Hopkins University, and a Ph.D. from Rutgers University, all in Electrical Engineering. He is a licensed professional engineer in the Commonwealth of Virginia. His research activities have been in the area of digital communication systems and coding theory. He is currently a co-PI on the NSF S-STEM grant at Rowan University, whose goal is to increase the number of technically proficient graduates who will contribute to the economic vitality of the region. 


\title{
CONFIGURATION AND ASSESSMENT OF A SENIOR LEVEL COURSE IN BIOMETRIC SYSTEMS
}

\begin{abstract}
It is very important that modern topics be covered at the senior undergraduate level in order that students benefit from (1) advanced STEM concepts, (2) project based learning, (3) a systems level perspective and (4) real world applications. This will help students that proceed to graduate school and who take up employment in government or industry. This paper describes a senior level undergraduate course in biometrics, a multidisciplinary area that is highly relevant to society and which has a rapidly growing global market. The course objectives, broad learning outcomes and curricular plan are described. Assessment results based on the analysis of a concept inventory test and student surveys (target versus control group) related to the learning outcomes show that the course was very successful.
\end{abstract}




\section{INTRODUCTION}

Modern topics are continuously being introduced at the junior and senior undergraduate level. These topics include but are not limited to power systems [1], systems engineering [2], embedded system design [3], system-on-chip [4][5], green engineering [5] and biomedical engineering [6]. This keeps the curriculum current, prepares students for either graduate school or employment, introduces advanced STEM concepts and provides a systems perspective.

This paper introduces the curricular and assessment details of a senior level course in biometric systems. Biometrics is the science of recognizing and authenticating people using their physiological features [7][8][9]. By using biometrics, it is possible to establish an identity based on "who you are", rather than by "what you possess" (e.g., an ID card) or "what you remember" (e.g., a password). Interest in biometrics has increased significantly with a global market that is experiencing very rapid growth. Border and immigration control, restricted access to facilities and information systems, cybersecurity, crime investigations and forensic analysis are just a few of the primary application areas of biometrics used by commercial, government and law enforcement agencies. There is much research interest in different biometric systems with the main issues being high performance, ease of use and implementation, low cost and high user acceptance. This course involves the study and design of various biometric systems (fingerprints, voice, face, iris and other modalities). Multibiometric systems are also covered. This includes feature fusion, classifier fusion and systems that use two or more biometric modalities. Biometric system performance and issues related to the security, ethics and privacy aspects of these systems will also be addressed.

There is an acute need for biometrics education at the undergraduate and graduate levels. Institutions world-wide have an established graduate program in biometrics and offer senior level undergraduate elective courses [10][11] in the area. The University of West Virginia offers a Bachelor of Science in Biometric Systems. The U.S. Naval Academy has a Biometrics Research Laboratory with an aim to enhance undergraduate biometrics education [11] where a senior undergraduate elective course on Biometric Signal Processing is offered that integrates lecture and laboratory experiences.

\section{COURSE OBJECTIVES}

The course objectives are given below. A Signals and Systems course is the prerequisite.

1. To develop a thorough understanding of the components of a biometric system, the concepts of verification and identification, system errors, 
performance measures, biometric applications, ethical and privacy issues and biometric security.

2. To understand the basic concepts of pattern recognition including preprocessing, feature extraction, classifier implementation and data fusion.

3. To design and achieve a software implementation of at least one biometric modality.

4. To perform a case study of a practical biometric system.

\section{LEARNING OUTCOMES}

The student learning outcomes of the project include:

- Enhanced application of math skills.

- Enhanced software implementation skills.

- Enhanced interest in biometrics.

- Enhanced ability to read papers and apply algorithms (like robust feature extraction) to achieve a better design thereby providing research experience.

- Enhanced communication skills.

- Comprehension of the importance of vertical integration: Students realize that their experiences are part of a flow that contributes to a unified knowledge base.

\section{TOPICAL OUTLINE AND PEDAGOGY}

The list of topics to be covered is as follows:

1. Introduction to Biometrics: Components of a biometric system, the concepts of verification and identification, system errors, performance measures, biometric applications, ethical and privacy issues and biometric security.

2. Fundamentals of Pattern Recognition

3. Face Recognition

4. Fingerprint Recognition

5. Speaker Recognition

6. Iris Recognition

7. Biometric System Security

Although concepts covered in a typical Signals and Systems course is assumed knowledge, no background in pattern recognition is required. Hence, the first two topics take time to cover. It is important to cover the basics very well and give many examples of the practical uses of biometrics and where it is deployed. In covering pattern recognition, four classifiers [12][13][14] are covered, namely, k nearest neighbor (kNN), vector quantizer (VQ), neural networks (NN) and Gaussian mixture models (GMM). A systems perspective is taken to cover the modalities of face, fingerprint, speaker and iris 
recognition with a focus on preprocessing and feature extraction. It is a challenge to cover security and one has very little time for this topic.

The course includes homework, quizzes, a case study and a final project. The homework includes reading assignments, analytical problems and software based questions. Examples are as follows:

1. Write a 700-1000 word synopsis of the article given below demonstrating your understanding of the article. You do not have to get into mathematical details. The synopsis should show your conceptual understanding.

Article [15]:

Amin Fazel and Shantanu Chakrabartty, An Overview of Statistical Pattern Techniques for Speaker Verification, IEEE Circuits and Systems Magazine, June 2011.

2. Write a MATLAB program that implements the LBG algorithm with the following inputs and outputs:

Input: Training data vectors of any finite dimension, desired codebook size equal to a power of 2 .

Output: Codebook of the desired size.

Discuss briefly how this program could be modified to design a codebook of a size that is not a power of 2 .

Test your program by designing a codebook of size 1,2 and 4 for the training data of dimension 3 given by: [1 2 5], [-4 6 8], [2 0 -1], [-1 -2 5], [2 3 8], [10 5 -6], [109 4], [-2 -4 -7], [3 1 -2], [0 0 0], [2 3 -8], [11 2 -6], [3 -2 1], [6 -6 6],[-5 10 -15].

3. Consider a training set $\mathrm{T}$ consisting of $\mathrm{M}>1$ real vectors of dimension $\mathrm{p}$. The training set is used to configure a VQ codebook of size 1 with the L1 distance measure given by

$$
d(x, y)=\sum_{i=1}^{p}|x(i)-y(i)|
$$

where $\mathrm{x}$ and $\mathrm{y}$ are real vectors of dimension $\mathrm{p}$. The components of $\mathrm{x}$ and $\mathrm{y}$ are $\mathrm{x}(\mathrm{i})$ and y(i) respectively. Prove that the optimal codebook of size 1 is the median of the vectors in $\mathrm{T}$.

Students do a case study of a biometric system deployed in actual practice. A class presentation of this study is given. Examples include:

1. Iris recognition in Dubai airport.

2. Fingerprint system in Disneyworld.

3. US VISIT Program

4. Privacy issued: Medical records 
5. Biometric passport

6. Transportation security (Airport, Train station, Bus station and others)

7. Electronic commerce

8. Wireless network security

9. Spoof detection

10. Biometrics in commercial applications (grocery stores, hotels and others)

11. Biometrics in forensics (criminal justice, corpse identification, disaster victim identification and others)

12. Biometrics and Smart Cards (federal identity cards)

13. Use of multibiometrics

14. Law, policy and ethical concerns

\section{DESCRIPTION OF PROJECT}

The course project can be on any biometric modality. The aim is to have certain attributes that teach concepts and skills. These include:

1. Software (MATLAB) implementation of an entire system.

2. Exposure to a standard database.

3. Signal acquisition in MATLAB from a standard database.

4. Preprocessing and feature extraction.

5. How does one train a system? This is classifier dependent.

6. How does one test a system and do performance evaluation? This is also classifier dependent.

7. Performance degradation due to mismatched training and testing conditions.

8. Open-ended design to augment performance due to mismatched training and testing conditions.

\section{Speaker Identification Project [16]}

One example is a speaker identification project using the King database [16]. The KING corpus [16] was created for research in the area of speaker identification. It was collected at two locations, namely, San Diego (26 speakers) and New Jersey (25 speakers). There are ten sessions for each speaker (numbered 01 to 10). Sessions were recorded a week to a month apart. The speech was passed through a standard telephone handset, transmitted through a local telephone exchange to a long distance service and back to the local exchange and then recorded from an analog telephone patch. There is both narrow-band communication channel and noise distortion. The speech is sampled at $8 \mathrm{kHz}$.

In this project, the 26 San Diego speakers are investigated. A peculiar anomaly of the narrow-band San Diego data is the phenomenon known as "The Great Divide". There is 
an apparent change in the spectral characteristics of the narrow-band channel between sessions 1-5 and sessions 6-10. This involves a difference in spectral slope for the composite transfer functions in the two sets. Speaker identification algorithms generally perform well within the divide and perform poorly across the divide as a result. It is a challenge to get a high performance across the divide. Performance evaluation across the great divide is an excellent example of mismatched training and testing conditions.

The deliverables for the project are a formal report and MATLAB code organized in a modular fashion with a brief description on how to run the code. A vector quantizer (VQ) classifier is prescribed. Specific project tasks include:

1. Listen to the speech files. Are there any perceivable differences "across the divide”?

2. Train on sessions s01 to s05, one at a time. Use VQ codebooks of size 64. Record the speaker identification accuracy for the nine remaining test sessions for seven different channel robust features.

3. Compare the performance of the features.

Suggestions for open-ended design include but are not limited to:

1. Research other robust features.

2. Examine feature fusion strategies. Examples are decision level fusion, probability level fusion and Borda count.

\section{Face Identification Project [17]}

The project described in [17] only involved using a neural network classifier [14]. The present version of the project has been improved to include the study of more classifiers. The first part of the project is to gain familiarity with the AT\&T database which is freely downloadable and contains a set of 400 face images. There are ten different images of each of 40 distinct subjects. For some subjects, the images were taken at different times, varying the lighting, facial expressions (open / closed eyes, smiling / not smiling) and facial details (glasses / no glasses). All the images were taken against a dark homogeneous background with the subjects in an upright, frontal position (with tolerance for some side movement).

Students are exposed to different functions in the Image Processing Toolbox of MATLAB including the reading of the image files (which are in PGM format) and displaying the images. The size of each image is 112 by 92 pixels, with 256 grey levels per pixel. Students learn the feature extraction step of converting an image to a 2-D DCT and scanning the 2-D DCT in a 'zigzag' fashion to get a 1-D feature vector [18]. Figure 1 
depicts this concept. Students plot the feature vectors of the same subject and different subjects to comprehend the concepts of intraclass variability and interclass similarity.
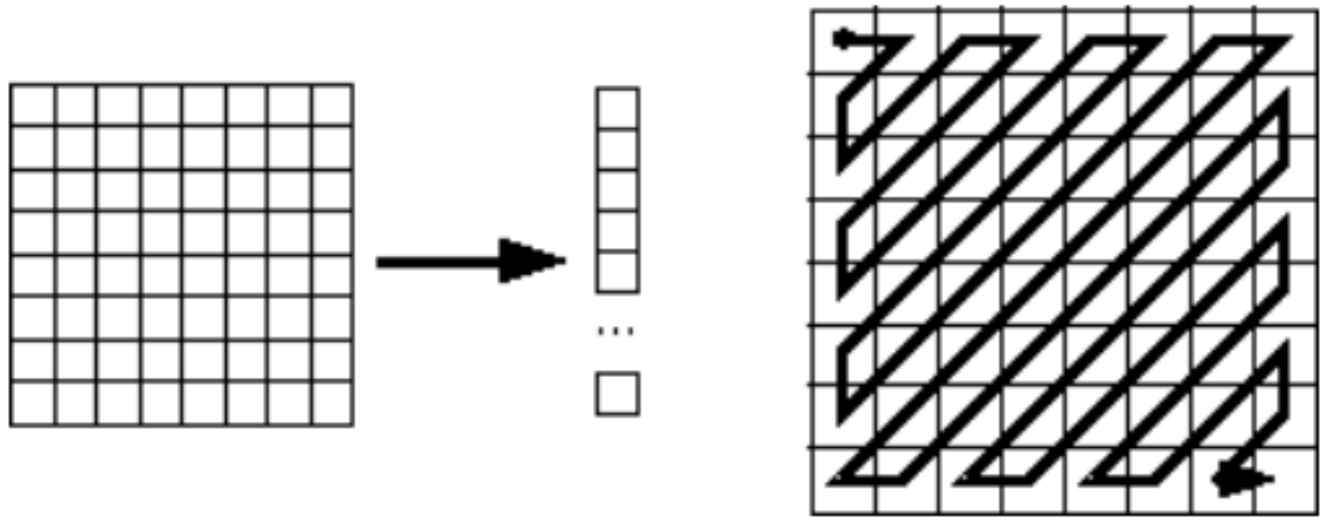

Figure 1. A 'zigzag' scanning of a 2-D DCT array to get a 1-D feature vector (taken from [17])

In addition to the tasks above, students are asked to do the following:

1. Implement a face identification system for all 40 subjects such that 5 images are used for training and 5 are used for testing (or performance evaluation).

2. Use the scanned 1-D DCT as the feature vector and experiment to see the effect of different vector dimensions on performance.

3. Compare the performance of a $\mathrm{k}$ nearest Neighbor $(\mathrm{kNN})$, weighted $\mathrm{kNN}$, vector quantizer (VQ) and neural network classifier. For the weighted kNN, design your own weighting scheme. The multilayer perceptron (MLP) with one hidden layer is recommended as the neural network.

4. For the $\mathrm{kNN}$ and weighted $\mathrm{kNN}$, what is the effect of $\mathrm{k}$ on the performance?

5. For the neural network, what is the effect of the number of hidden layer nodes on performance?

Suggestions for open-ended design include but are not limited to:

1. Research other features.

2. Examine classifier fusion strategies.

3. Use the Gaussian Mixture Model classifier [19] in combination with the SMOTE algorithm [20] to generate more training data. The GMM requires much training data to be successful. A MATLAB code to implement smote (smote.m) was emailed to the class.

The deliverables for this project are also a formal report and MATLAB code organized in a modular fashion with a brief description on how to run the code. 


\section{ASSESSMENT RESULTS}

The assessment results are based on the course material and the face recognition project as this project was given the last time the course was taught.

\section{Student Surveys}

The senior class was divided into a target and control group. Surveys for both groups were conducted. The first four questions are common to both surveys. The control group consists of two sets of students, namely, (1) students in the biometrics class who are surveyed at the beginning of the semester before being exposed to the course material and the project and (2) students who did not do the project since they were not in the biometrics class. This control group has 27 students. The target group consists of the 16 students who are in the biometrics class who are surveyed at the end of the semester.

We first analyze the results of the first four questions so that the target and control groups can be compared. In question 1, 14 areas in ECE are listed and students are asked to rate their interest in each area on a scale of 1 (not at all interested) to 5 (very interested). The true intent of this question is to assess student interest in areas related to biometrics. This true intent is hidden from the student participants. Among the list, there are three areas related to biometrics. Table 1 shows the results comparing the target and control groups. A two sample statistical t-test with a 5\% significance level and unequal variances [21] is performed to determine if the score for the target group is significantly better than the score for the control group. A p-value of less than 0.05 indicates a statistically significant difference.

\begin{tabular}{|l|l|l|l|}
\hline Interest in Course & $\begin{array}{l}\text { Target (Mean, } \\
\text { Median, Standard } \\
\text { Deviation) }\end{array}$ & $\begin{array}{l}\text { Control (Mean, } \\
\text { Median, Standard } \\
\text { Deviation) }\end{array}$ & p-value \\
\hline Image Processing & $3.94,4.00,1.1815$ & $3.59,4.00,1.3661$ & $\begin{array}{l}0.1945, \text { not } \\
\text { significant }\end{array}$ \\
\hline Speech Processing & $3.56,4.00,1.4127$ & $3.04,3.00,1.1596$ & $\begin{array}{l}0.1096, \text { not } \\
\text { significant }\end{array}$ \\
\hline Biometrics engineering & $3.88,4.00,1.2583$ & $3.00,3.00,1.3009$ & 0.0184, significant \\
\hline
\end{tabular}

\section{Table 1 - Scores and p-value for Target and Control Group for Interest in Certain Courses (Question 1)}

In question 2, a list of 22 elective courses (with generic titles) is given and students rate their interest in taking each on a scale of 1 to 5 . A combined score is calculated using six 
courses relevant to biometrics, namely, computer forensics, biometric signal processing, machine learning, digital image processing, pattern recognition and biometric security technologies. For questions 3 and 4, fourteen subject areas are given. For question 3, students rate each area in terms of pursuing a graduate degree. In question 4 , students rate their interest in pursuing a career. A combined score is calculated using five subject areas related to biometrics, namely, image processing, computer forensics, machine learning, biometrics and speech processing. Table 2 gives the results. For questions 2 and 4, there is a statistically significant difference in the target and control groups. For question 3 , the p-value is very close to 0.05 .

\begin{tabular}{|l|l|l|l|}
\hline Question & $\begin{array}{l}\text { Target (Mean, } \\
\text { Median, Standard } \\
\text { Deviation) }\end{array}$ & $\begin{array}{l}\text { Control (Mean, } \\
\text { Median, Standard } \\
\text { Deviation) }\end{array}$ & p-value \\
\hline $\begin{array}{l}\text { 2 - Interest in Elective } \\
\text { Courses }\end{array}$ & $3.73,4.00,1.3177$ & $3.44,3.50,1.3372$ & 0.0449 , significant \\
\hline $\begin{array}{l}\text { 3- Interest in Pursuing a } \\
\text { Graduate Degree }\end{array}$ & $3.40,4.00,1.2284$ & $3.11,3.00,1.3364$ & $\begin{array}{l}0.0543, \text { not } \\
\text { significant }\end{array}$ \\
\hline $\begin{array}{l}\text { 4- Interest in Pursuing a } \\
\text { Career }\end{array}$ & $3.35,3.00,1.3510$ & $2.78,3.00,1.3858$ & 0.0017, significant \\
\hline
\end{tabular}

Table 2 - Scores and p-value for Target and Control Group for Questions 2 to 4

Table 3 shows the results for questions that were exclusively asked to the target group. Students rated each statement on a scale of 1 to 5 (1-Strongly disagree, 2-Disagree, 3Neutral, 4- Agree and 5-Strongly Agree). For all the statements, the median score was at least 4 indicating that many learning outcomes were achieved. The high standard deviations are due to the relatively small number of students in the target group coupled with the variation in the opinions.

With respect to student perception of vertical integration, the majority of the students felt that previous courses in mathematics (calculus and linear algebra), signals and digital signal processing were the most relevant. Courses in physics (mechanics and electricity), chemistry and analog circuits were expectedly not relevant.

\section{Concept Inventory Test [22][23]}

At the end of the semester, a concept inventory test consisting of 6 multiple choice questions, 3 filling in the blank questions, 3 short answer and 1 problem (relating to biometric identification using a kNN classifier) was given. The mean score was $76 \%$ and the median score was $81 \%$. The students scored lowest on the problem. While this result demonstrates reasonable achievement of the instructional objectives, the instructor plans 
to improve the course in future offerings by making homework problems more rigorous. In the next offering of the course, the procedure in [22][23] will be followed, conducting a test at the beginning and end of the semester in order to do a statistical evaluation of student learning.

\begin{tabular}{|l|l|l|l|}
\hline Statement & Mean & Median & $\begin{array}{l}\text { Standard } \\
\text { Deviation }\end{array}$ \\
\hline $\begin{array}{l}\text { The laboratory project as a whole helped reinforce } \\
\text { MATLAB software skills. }\end{array}$ & 4.06 & 4 & 0.7719 \\
\hline $\begin{array}{l}\text { The laboratory project as a whole helped reinforce written } \\
\text { communication skills. }\end{array}$ & 3.56 & 4 & 0.6292 \\
\hline $\begin{array}{l}\text { The laboratory project provided me with a basic background } \\
\text { in pattern recognition/biometrics. }\end{array}$ & 4.19 & 4 & 0.9106 \\
\hline $\begin{array}{l}\text { The open-ended part of the laboratory project helped me gain } \\
\text { research experience on the performance aspects of biometric } \\
\text { systems. }\end{array}$ & 4.06 & 4 & 0.6801 \\
\hline $\begin{array}{l}\text { This course has achieved its objective of raising awareness } \\
\text { of biometrics as a field. }\end{array}$ & 4.19 & 4.5 & 0.9106 \\
\hline $\begin{array}{l}\text { This course has achieved its objective of providing me with a } \\
\text { fundamental background by addressing a broad spectrum of } \\
\text { topics in biometrics. }\end{array}$ & 4.19 & 4 & 0.6551 \\
\hline $\begin{array}{l}\text { I believe that the knowledge set and skills I have obtained in } \\
\text { this class make me better qualified for graduate study and/or } \\
\text { career options in biometrics. }\end{array}$ & 3.94 & 4 & 0.9287 \\
\hline $\begin{array}{l}\text { I am now more likely to follow popular media news / } \\
\text { developments / programs that relate to biometrics as } \\
\text { compared to the beginning of the semester. }\end{array}$ & 3.69 & 4 & 1.0782 \\
\hline
\end{tabular}

Table 3 - Target Group Project Survey Results

\section{SUMMARY AND CONCLUSIONS}

A senior level elective in biometrics is described. The central feature of the course is a project in which students implemented a complete system, did a performance evaluation and understood one of the main problems in biometrics research, namely the lack of robustness due to mismatched training and testing conditions. Preliminary data suggests that the senior level biometrics course has achieved many learning outcomes, given the students a perception of the usefulness of vertical integration and stimulated interest in biometrics. Surveys conducted after the project revealed that the students perceived the project as successful in meeting the desired learning outcomes. Target versus control group surveys show that students who completed the project have more interest in biometrics than their peers who did not. Assessment activities will be expanded in future offerings of the course. 


\section{ACKNOWLEDGEMENT}

This work was supported by the National Science Foundation through TUES Type 2 Collaborative Research Grants DUE-1122296, DUE-1122344 and DUE-1122299.

\section{REFERENCES}

1. Y. Liao, "Development of a New Power System Course: Power System Analysis Using Advanced Software”, ASEE Annual Conference, San Antonio, Texas, June 2012.

2. C. S. Wasson, "'System Engineering Competency: The Missing Course in Engineering Education”, ASEE Annual Conference, San Antonio, Texas, June 2012.

3. O. Farook, C. R. Sekhar, J. P. Agrawal and A. Ahmed, "Multiprocessor Embedded System Design: A Course With Hardware/Software Integration”, ASEE Annual Conference, San Antonio, Texas, June 2012.

4. Y. Tang, L. M. Head, R. P. Ramachandran and L. Chatman, "Integrating System on Chip in an Undergraduate ECE Curriculum”, ASEE Annual Conference, Austin, Texas, June 2009.

5. R. P. Ramachandran, P. Jansson, Y. Tang, L. M. Head and L. Chatman, "Vertical Integration of System-on-Chip and Green Engineering Across the Undergraduate Curriculum”, IEEE Frontiers in Education Conference, Arlington, Virginia, Session T3J, October 27-30, 2010.

6. S. Jacques, J. D. Gassert, T. Swiontek, J. LaMack, C. Tritt, L. Fennigkoh, R. Gerrits, V. Canino and N. Schlick, "Biomedical Engineering Curricula: Producing the Engineers of 2020”, ASEE Annual Conference, Austin, Texas, June 2009.

7. A. K. Jain, A. A. Ross and K. Nandakumar, Introduction to Biometrics, Springer, 2011.

8. A. K. Jain, P. Flynn and A. A. Ross, Handbook of Biometrics, Springer, 2008.

9. A. K. Jain, A. Ross and S. Prabhakar, "An introduction to biometric recognition", IEEE Transactions on Circuits and Systems for Video Technology, Vol. 14, No. 1, January 2004.

10. S. Cotter, "Laboratory Exercises for an Undergraduate Biometric Signal Processing Course”, ASEE Annual Conference, Louisville, Kentucky, June 2010.

11. R. W. Ives, Y. Du, D. M. Etter and T. B. Welch, "A Multidisciplinary Approach to Biometrics”, IEEE Transactions on Education, Vol. 48, No. 3, pp. 462-471, August 2005. 
12. C. M. Bishop, Pattern Recognition and Machine Learning, Springer, 2006.

13. I. T. Nabney, NETLAB: Algorithms for Pattern Recognition, Springer, 2002.

14. S. Haykin, Neural Networks: A Comprehensive Foundation, Prentice-Hall, 1999.

15. Amin Fazel and Shantanu Chakrabartty, An Overview of Statistical Pattern Techniques for Speaker Verification, IEEE Circuits and Systems Magazine, June 2011.

16. R. P. Ramachandran, R. Polikar, K. D. Dahm and S. S. Shetty, “'Open-Ended Design and Performance Evaluation of a Biometric Speaker Identification System”, IEEE Int. Symp. on Circuits and Systems, Seoul, South Korea, pp. 2697_2700, May 20_23, 2012.

17. R. P. Ramachandran, R. Polikar, K. D. Dahm, Y. Tang, S. S. Shetty, R. J. Kozick, R. M. Nickel and S. H. Chin, 'Project Based Design of a Biometric Face Recognition System”, ASEE Annual Conference and Exhibition, San Antonio, Texas, June 10--13, 2012.

18. T. Bose, Digital Signal and Image Processing, Wiley, 2004.

19. I. T. Nabney, “NETLAB: Algorithms for Pattern Recognition”, Springer, 2002.

20. N. Chawla, K. Bowyer, L. Hall and W. Kegelmeyer, "SMOTE: Synthetic Minority Over-Sampling Technique”, Journal of Artificial Intelligence Research, pp. 321-357, 2002.

21. R. D. Yates and D. J. Goodman, Probability and Stochastic Processes John Wiley, 1999.

22. K. E. Wage, J. R. Buck, C. H. G. Wright and T. B. Welch, 'The Signals and Systems Concept Inventory”, IEEE Transactions on Education, Vol. 48, No. 3, pp. 448-461, August 2005.

23. J. R. Buck and K. E. Wage,, “Active and Cooperative Learning in Signal Processing Courses”, IEEE Signal Processing Magazine, Vol. 2, No. 2, pp. 76-81, March 2005. 